\title{
Regeneration of Axons and Synaptic Connections by Touch Sensory Neurons in the Leech Central Nervous System ${ }^{1}$
}

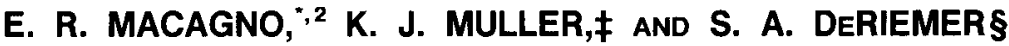

${ }^{\star}$ Department of Biological Sciences, Columbia University, New York, New York 10027, $\ddagger$ Department of Physiology and Biophysics, University of Miami School of Medicine, Miami, Florida 33101, and \$Max Planck Institut für biophysikalische Chemie, Göttingen, West Germany

\begin{abstract}
In studies of axonal regeneration, it has been difficult to determine (a) whether growth along the normal pathway is important for restoration of connections with previous targets and $(b)$ whether the new synapses resemble the old in strength and location. To address these problems at the level of individual nerve cells, we have studied touch $(T)$ sensory neurons in the leech after their axons have been severed and we have confirmed that their axons regenerate electrical connections with some of their usual synaptic targets in the central nervous system. Injections of horseradish peroxidase and Lucifer Yellow dye into separate $\mathrm{T}$ cells in unoperated animals showed that $T$ cell axons typically run close to one another within single ganglia or from ganglion to ganglion. Knowledge of one $T$ cell's arborizations thus revealed the groundplan of others in the same ganglia and the sites of apparent contact with its synaptic targets. For regenerating axons, those sprouts that encountered the normal pathway (as marked by homologous axons) grew preferentially along it. Despite the striking coincidence of old and new pathways, regenerated branching patterns within the ganglionic neuropils were usually incomplete and sometimes had atypical branches. Synaptic connections with normal targets (other T cells as well as $\mathbf{S}$ and $C$ cells) were abnormally weak physiologically. The numbers of apparent contacts seen with the light microscope were also lower than normal. In addition, the strength of the synaptic potentials, normalized to the number of contacts (calculated as microvolts per contact), was generally smaller in the regenerated connections than in the controls, and smallest at earliest times, during the first 6 weeks following injury. It thus appears to be characteristic of $T$ cell regeneration that axon regrowth is aided by the recognition of specific pathways and that successful regeneration, as assayed anatomically and physiologically, occurs frequently but usually incompletely.
\end{abstract}

The selection of synaptic targets by a neuron depends upon

Received December 10, 1984; Revised February 7, 1985;

Accepted February 12, 1985

${ }^{1}$ We thank Walter Stewart for the gift of Lucifer Yellow $\mathrm{CH}$ and John Nicholls for his criticisms of the manuscript. This research was supported in part by National Institutes of Health Grants NS-14946, NS-20336, and NS20607, and by a McKnight Neurosciences Development Award to K. J. M. The computer work was carried out at the Columbia Computer Graphics Facility under National Institutes of Health Grant RR-0042.

${ }^{2}$ To whom correpondence should be addressed. directed growth of axons and dendrites and on a matching or compatibility of cells. What directs growing neurons and how much flexibility there is in pathway and target selection remain important questions. Neurons are able to grow axons and select targets accurately in many adult animals, including leeches (Muller, 1982). In the leech central nervous system it has been shown that individual neurons can regenerate severed axons to reconnect with particular cells known to be among their normal synaptic targets (Muller and Nicholls, 1981). However, the physiological studies of synapse regeneration have not shown whether synapses in the neuropil form in their normal locations or whether regenerating axons grow abnormally and find the normal targets at ectopic locations. This problem is addressed here.

The touch sensory neurons ( $T$ cells) in the leech were the first neurons in any species shown to reconnect with specific other neurons (Baylor and Nicholls, 1971), and they are the focus of the present morphological and physiological study. In each half (right or left) of the ganglion, or hemiganglion, there are three T cells in which receplive fields partition the skin approximately into thirds. Their axons innervate the ventral, lateral, and dorsal skin of their own segments (Nicholls and Baylor, 1968) and of adjacent segments, which they reach through neighboring ganglia ( $Y a u, 1976)$. T cells make electrical synapses with other $T$ cells (Baylor and Nicholls, 1969) and certain other neurons (Muller and Scott, 1981) in the neuropils of their own and of adjacent ganglia. From one ganglion to the next there is variability in the precise pattern of $T$ cell secondary branches that emerge, like the teeth of a comb, from the laterally running primary axon. However, the secondary processes of all three $T$ cells on each side of the ganglion have a striking coincidence of position, as if they had grown along one another, and display numerous sites at which they appear to be in contact (DeRiemer and Macagno, 1981).

We now show that $T$ cell axons also follow their homologues in adjacent ganglia nearly branch for branch. Thus, the processes of one $T$ cell delineate for us the normal pathways of other $T$ cells within the ganglion, which otherwise has few obvious landmarks. $T$ cells appear to contact one another mainly at the many swellings or varicosities shown to be the sites of synapses along the secondary branches within ganglia (Muller and McMahan, 1976; Muller, 1979). By using separate intracellular markers in combination with computer-assisted analysis of branching patterns and points of contact, we have been able to determine the accuracy of regenerative growth and compare it with the return of function.

Some aspects of this study have been reported in preliminary form (DeRiemer et al., 1981; Macagno et al., 1982).

\section{Materials and Methods}

Leeches (Hirudo medicinalis) were obtained from suppliers in France (Ricarimpex, 33980 Audenge, Bordeaux) and West Germany (Blutegel Import 
und Versand, Rontgenstrasse, Recklinghausen-Sud), and maintained at $15^{\circ} \mathrm{C}$ in artifical spring waler (0.5 ym of solid Forty Fathorns artifical seawater (Marine Enterprises, Towson, MD) per liter of water; Muller and Scott, 1979). For operations, animals were anesthetized in $8 \%$ ethanol in spring water, and the ventral nerve cord was crushed with fine forceps or, in a few cases, cut with iridectomy scissors through a small incision in the ventral body wall (Baylor and Nicholls, 1969; Muller and Carbonetto, 1979). In most cases a single crush was made just posterior to each of two or three widely separated mid-body segmental ganglia, and regeneration into these ganglia was followed. Because of the low incidence of $T$ cell regeneration after a cut (see Table II), the present paper focuses on recovery from crushing.

After periods ranging from 1 day to 4 years, ganglia in chains of three were dissected from the animal and placed in modified leech salinc consisting of $100 \mathrm{~mm} \mathrm{NaCl}, 1.8 \mathrm{mM} \mathrm{CaCl}_{2}, 4 \mathrm{mM} \mathrm{KCl}, 15 \mathrm{mM} \mathrm{MgCl}_{2}$, and $10 \mathrm{~mm}$ Tris maleate, $\mathrm{pH}$ 7.4. The $\mathrm{Mg}^{2+}$, which mole for mole replaced $\mathrm{Na}^{+}$in normal leech saline, was used to reduce or block chemical synaplic Iranismission (Nicholls and Purves, 1970). Synaptic connections were tested between pairs of cells using standard physiological recording techniques (e.g., Appendix $\mathrm{C}$ of Muller et al., 1981), and signals were stored on magnetic tape at $4 \mathrm{kHz}$ bandwidth and also averaged using a Dagan signal averager. All cells studied had resting potentials equal to or greater than $-40 \mathrm{mV}$. In each chain of three ganglia the lesion was located between the two more posterior ganglia. The efficacy of synaptic transmission between lesioned T cells in the most posterior ganglion and target $S$ or $T$ cells in the middle ganglion was compared with the synaptic potential elicited in these same target cells by the posterior branching fields of unlesioned $T$ cells in the most anterior ganglion. These control synaptic responses were comparable to those observed in unlesioned animals. No "spontaneous" synaptic potentials occurred in solutions containing elevated $\left[\mathrm{Mg}^{2+}\right]$; each sweep was viewed to confirm that such signals did not appear. In controls, the averaged responses were absent when recording outside postsynaptic cells or in the neuropil, or from certain cells that had not become contacted in the same group, suggesting that the responses were true synaptic potentials. For recordings between T cells and the S interneuron, the medial connective (Faivre's nerve) was cut between ganglia to prevent spread of signals between $S$ cells.

A $T$ cell, preferably one that had been shown functionally to have regenerated, was injected with horseradish peroxidase (HRP) (Muller and McMahan, 1976) on each side of the ganglion posterior to the lesion, in most cases, and the preparation was placed in modified Leibowitz-15 medium (Ready and Nicholls, 1979) to allow the enzyme to travel throughout processes and beyond adjacent ganglia. The cells were reinjected with HRP half a day later, and after one full day a homologous, ipsilateral $\mathrm{T}$ cell in the adjacent ganglion on the other side of the crush ("target T cell") was injected with Lucifer Yellow Cll dye. Because the dorsal T cell has a branching pattern somewhat different from those of the other two $T$ cells, in the present study it was examined less often, as were the posteriorly projecting axons of all three $T$ cells. To examine the contacts between $T$ cells in one ganglion and coupling interneurons (C cells) or S cells (Muller and Scott, 1981) in the next, $S$ cells rather than $T$ cells were injected with Lucifer Yellow dye. In order to view both the HRP reaction product and the Lucifer-Yellow dye simultaneously, the reaction with diaminobenzidine was performed as previously described (DeRiemer and Macagno, 1981; Macagno et al., 1981) before fixation in $4 \%$ paraformaldehyde and mounting whole in methyl salicylate under coverslips sealed with clear fingernail polish. By freezing the mounted preparations, the fluorescence was preserved for months with little increase in background.

Counts of branches, varicosities, and likely contacts between cells were determined using $\times 100$ oil immersion objectives and with the aid of a computer, as previously described (DeRiemer and Macagno, 1981); in many cases arborizations of the injected cells were fully reconstructed in the target ganglia. Although in some cases growing processes were extremely fine except at distinctive beads or varicosities, electron microscopy suggests that even the finest sprouts can be detected with the light microscope (Mason and Muller, 1982; E. R. Macagno and K. J. Muller, unpublished observation). Preparations were photographed using combined epifluorescence and brightfield illumination or Nomarski interference optics.

\section{Results}

\section{Structure of regenerating axons}

The projections of $T$ cell axons into adjacent ganglia and association with $T$ cell homologues. The processes of the $T$ cells within each hemiganglion closely follow and make apparent contacts with one another in the neuropil, as shown by injections of $T$ cells with two separate markers (DeRiemer and Macagno, 1981). These apparent contacts occur for the most part at swellings or varicosities. The projections of the $T$ cells into adjacent ganglia resemble their arborizations within their own ganglia. (Yau, 1976), although quantitative analysis shows that projections in adjacent ganglia are simpler (Table I). Thus, it is not surprising that a T cell's projections within an adjacent ganglion course along the processes of a homologous T cell having its cell body in that ganglion (Fig. 1, $a$ and $b$ ). In fact, all nine $T$ cell arbors in each hemiganglion project branches along similar pathways in the neuropil, with a somewhat higher incidence of apparent contact and frequency of branching for ventral and lateral $T$ cells ( $T_{V}$ and $T_{L}$, respectively) than for the dorsal $\left(T_{D}\right) T$ cells, and with the great majority of apparent contacts between $T$ cells occurring at varicosities. Therefore, despite variability in the branching pattern from ganglion to ganglion, we are provided with a roadmap of the approximate course normally taken by all $T$ cell processes through the neuropil simply by examining one of the local $T$ cells. Such a roadmap is useful in the examination of the regenerates.

The $T$ cell axons also tend to follow one another from ganglion to ganglion within the connectives. In fact, all mechanosensory cell axons travel within the ventrolateral sextant of the connective, as viewed in cross-section, with a $95 \%$ probability (C. Kent and $\mathrm{K}$. Muller, unpublished observation).

$T$ cell association with coupling interneurons. In addition to associating with other $T$ cells, $T$ cells form apparent contacts, chiefly near the tips of their secondary branches, with the processes of a small pair of cells called coupling interneurons ( $C$ cells), with which they make electrical synapses. The $\mathrm{C}$ cells, in turn, are coupled to the $S$ interneuron and provide the link between $T$ cells, the $S$ cell, and the contralateral $T$ cells. (Ipsilateral $T$ cells are coupled even without the $C$ cells.) Not only are the $C$ cells strongly coupled to the $S$ cell via non-rectifying junctions, but small molecules of dye such as Lucifer Yellow pass readily from the $S$ cell to the $C$ cells. The $S$ cell can be readily penetrated and identified on the basis of its distinctive action potential and its location. The $C$ cells are considerably more difficult to find and are in practice marked by injection of dye into the $\mathrm{S}$ cell. Fluorescence in the $\mathrm{S}$ cell processes can be blocked by subsequent injection of the opaque marker HRP, which does not cross the cell's electrical junctions, leaving only the two $\mathrm{C}$ cells fluorescent (Muller and Scott, 1981). Figure 1C shows that the apparent contacts between $T$ cells and $C$ cells that have been reported within a single ganglion (Muller and Scott, 1981) also occur between the projections from $T$ cells in one ganglion and the $C$ cells confined to the next. Thus, one can ask, does the communication mediated by this set of apparent contacts recover with $T$ cell regeneration?

Early stages of regeneration. Within hours of injury to the connectives, the T cells on both sides of the lesion began to sprout. The sprouts grew in many directions, including back to the cell's own ganglion and away from the lesion as well as across it, some neurites reaching the other side of the lesion within 3 days (Table II). In spite

TABLE I

Numbers of secondary branches, varicosities, and contacts of $T$ cells in control ganglia

\begin{tabular}{lcccccc}
\hline \multirow{3}{*}{ Parameter } & \multicolumn{3}{c}{ Normal Animals } & & \multicolumn{2}{c}{ Operated Animals } \\
\cline { 2 - 4 } & $\begin{array}{c}\text { Main } \\
\text { Field }\end{array}$ & $\begin{array}{c}\text { Anterior } \\
\text { Field }\end{array}$ & $\begin{array}{c}\text { Posterior } \\
\text { Field }\end{array}$ & $\begin{array}{c}\text { Main } \\
\text { Field }\end{array}$ & $\begin{array}{c}\text { Anterior } \\
\text { Field }\end{array}$ \\
\hline Secondary branches & $36 \pm 9$ & $28 \pm 5$ & $27 \pm 5$ & $41 \pm 4$ & $28 \pm 6$ \\
& $(n=37)$ & $(n=8)$ & $(n=9)$ & $(n=6)$ & $(n=6)$ \\
Varicosities & $198 \pm 42$ & $133 \pm 23$ & $120 \pm 33$ & $326 \pm 35$ & $118 \pm 12$ \\
& $(n=37)$ & $(n=8)$ & $(n=9)$ & $(n=6)$ & $(n=6)$ \\
Contacts & $96 \pm 3$ & $40 \pm 12$ & $33 \pm 11$ & $N^{a}$ & $57 \pm 5$ \\
& $(n=4)$ & $(n=8)$ & $(n=9)$ & & $(n=6)$ \\
\hline
\end{tabular}

${ }^{a} \mathrm{ND}$, not determined. 

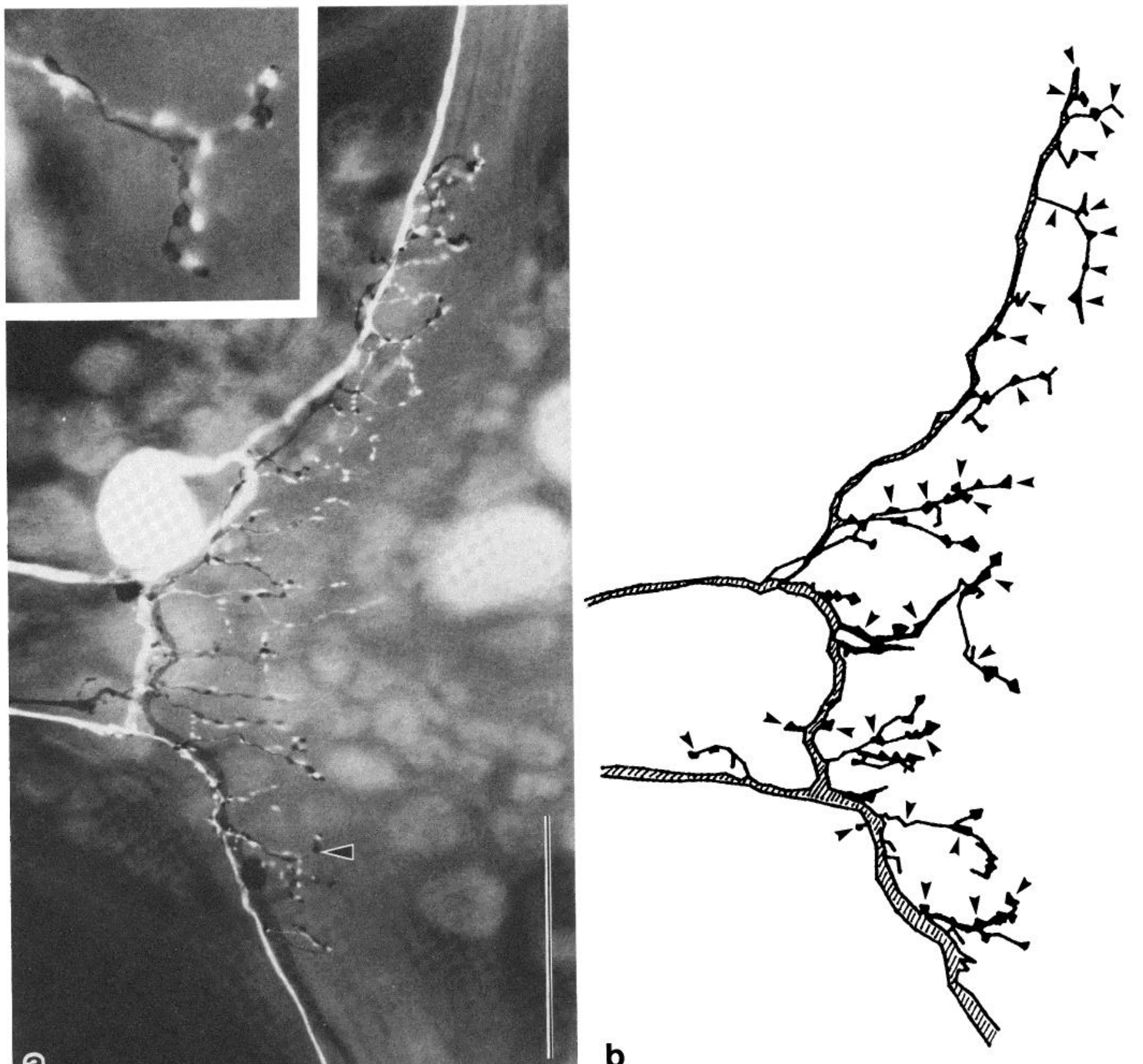

Figure 1. Morphology of anterior arbors of T cells in control ganglia and distribution of their apparent contacts with local T and C cells. a, Micrograph showing an HRP-filled anterior T cell and a T cell within the ganglion ("local") filled with Lucifer Yellow dye. The arrowhead points at the branch shown at higher magnification in the inset at upper left. Anterior is at the top and the view is dorsal in this and the following panels. $b$, Computer-aided drawing of a $\mathrm{T}$ cell anterior arbor in preparation different from the one shown in $a$. The locations of the 30 apparent contacts with a local T cell (not drawn) that were found are indicated by the arrowheads. Bar $=100 \mu \mathrm{m}$ ( $a$ and $b$ ). $c$. Camera lucida drawing of the anterior arbors of two T cells. The ganglion boundary and the cell bodies of the Retzius $(R)$ and $\mathrm{S}(S)$ cells are drawn. The $\mathrm{S}$ cell and the $\mathrm{C}$ cells were filled with Lucifer Yellow in this ganglion (thier arbors are not shown). The locations of contacts between the T cells and the $C$ cells are indicated by arrowheads. Bar $=100 \mu \mathrm{m}$. The high magnification micrograph (inset) shows the fluorescent $\mathrm{C}$ cell and the dark $\mathrm{T}$ cell in the region indicated by the open arrow in the drawing.

of the lack of order at the crush, growth was almost always restricted to the cells' own connective. An exception to this is shown in Figure 5 .

Full recovery was unusually rapid for a small and variable fraction of growing cells, each of which located the distal stump of a T cell axon, possibly its own, and reconnected with it so that molecules at least as large as $\operatorname{HRP}\left(M_{\mathrm{r}}=40,000\right)$ could travel without impediment into the distal stump (DeRiemer et al., 1983). No recovery was detected in less than two days. While the fraction of such fusions was in some studies $5 \%$ or even higher after narrow lesions, broader lesions or cuts reduced their number (DeRiemer et al., 1983; Table II). Rarely, the connection was made directly with a homologous T cell. The reconnection with the stump might have been facilitated by growth from the proximal end of the distal stump itself (Mason and Muller, 1982).

More often the regenerating axons did not reconnect with a distal stump but grew along the connectives into the target ganglion. Typically, one axon branch that had found the normal route, as 


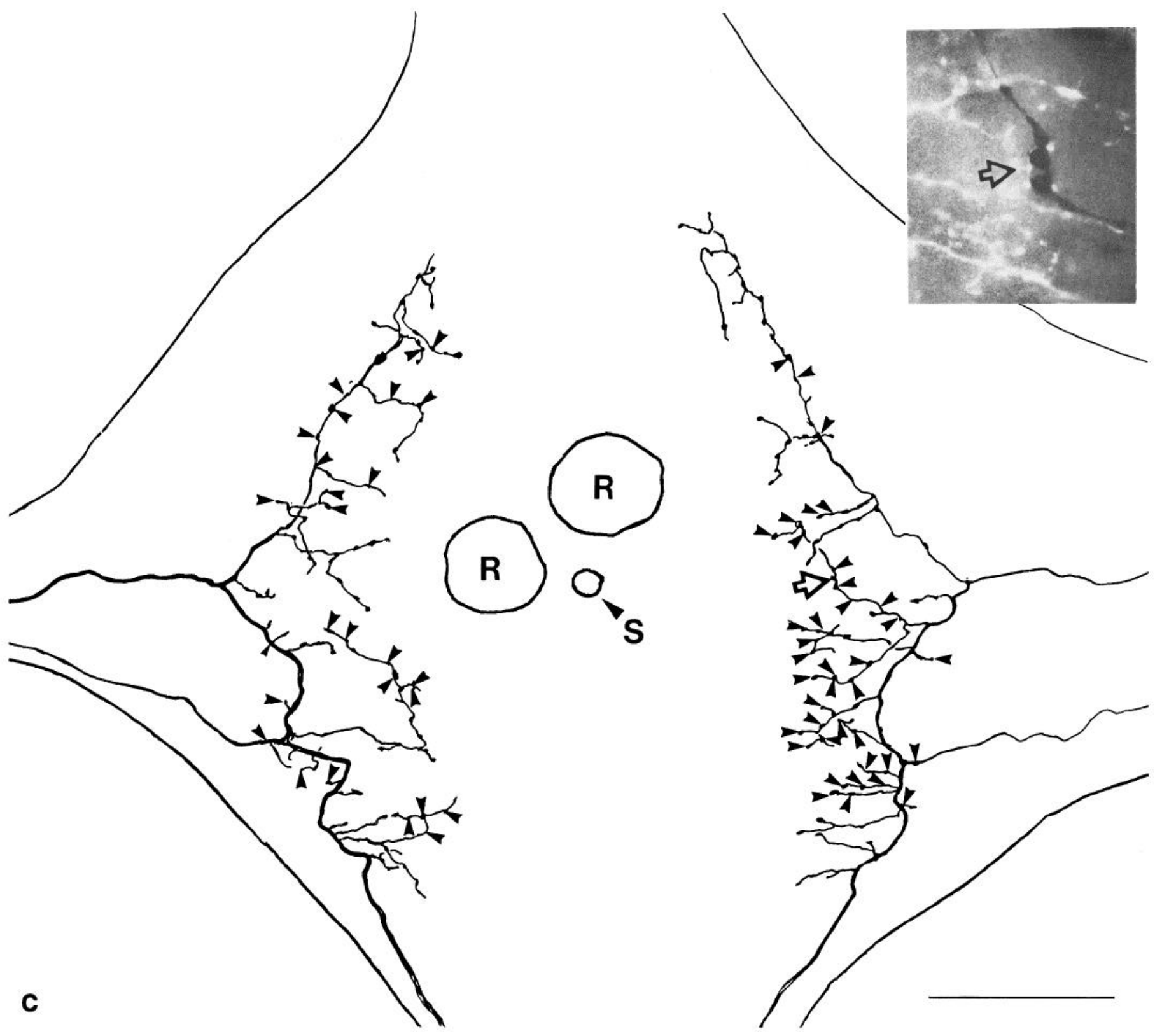

Figure $1 c$

marked by the axon of its homologue, grew preferentially into the target ganglion, whereas other branches grew less or retracted (Fig. 2). However, some notable exceptions occurred, as illustrated in Figures 4 and 5 .

Varicosities sometimes formed along neurites within connectives. These were probably sites of synapses that have been previously reported to be induced by connective lesions (Fernandez and Fernandez, 1974) and which are made by T cells upon other, unidentified neurons (Muller, 1979). As described below, however, no activity at such presumed ectopic synapses could be detected, perhaps because they are electrically distant from recording sites in the ganglion.

Arbor regeneration in the target ganglion. Growth into the ganglion occurred chiefly during the first 2 weeks after crushing, depending upon the distance between the lesion and the target ganglion. Varicosities, which normally are sites of chemical synapses made by $T$ cell axons that regenerate into adjacent ganglia (Muller, 1979), appeared along secondary processes in the neuropil as growth proceeded and were an important site of apparent contact between $T$ cells. Unlike the normal situation, however, a number of close appositions occurred at other locations. Figure 3 shows a typical pattern of growth into the ganglion in its early stages. The regenerated cell was stained with HRP 2 months after it had been injured about $2 \mathrm{~mm}$ from the target ganglion. Its few regenerated branches were concentrated in the posterior portion of the ganglion, there were only 53 varicosities and 27 apparent contacts with the Lucifer Yellow-stained target T cell, many of the apparent contacts were with the main axon of the target cell, and no processes had regenerated out of the segmental roots. This contrasts with the normal complement in an operated animal of 28 branches and 118 varicosities of the anterior branch of a $T_{V}$ or $T_{L}$ cell, and its 57 apparent contacts with its homologue in the anterior adjacent ganglion (Table I).

In general, regeneration was more complete at later times, but the correlation was only rough. Figure 4 depicts a later stage of regeneration than that for Figure 3 , and in both cases the regenerating 

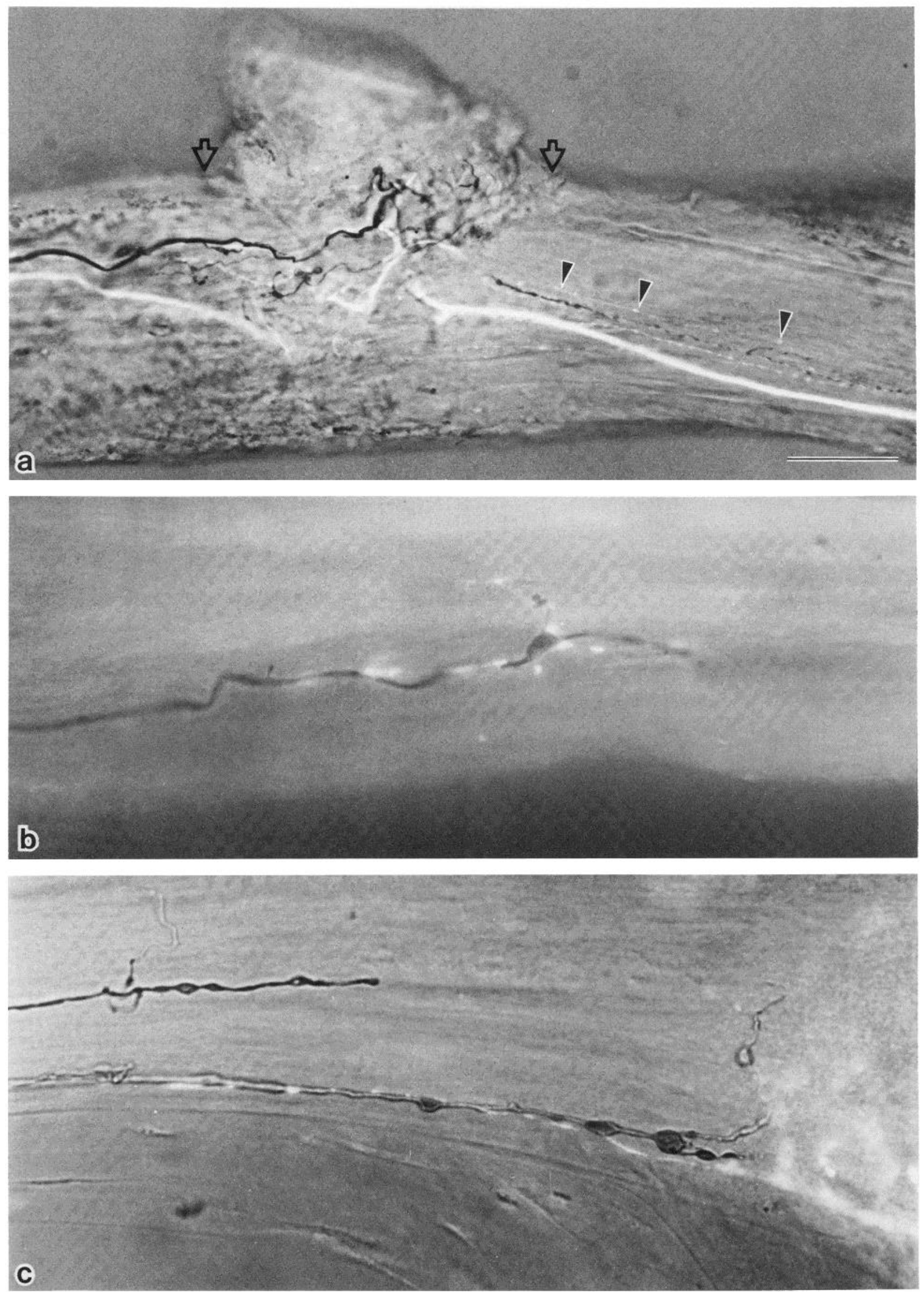
TABLE ॥

Numbers of $T$ cells showing various degrees of regeneration following the crushing or cutting of the connectives

\begin{tabular}{|c|c|c|c|c|c|c|c|}
\hline \multirow{2}{*}{$\begin{array}{l}\text { Regeneration } \\
\text { Time }^{a}\end{array}$} & \multicolumn{7}{|c|}{ Level of Regencration ${ }^{b}$} \\
\hline & $\begin{array}{l}\text { Total No. } \\
\text { Examined }\end{array}$ & 0 & A & B & $\mathrm{C}$ & D & $E$ \\
\hline \multicolumn{8}{|c|}{ A. Following Crushing of Connectives } \\
\hline \multicolumn{8}{|l|}{ Days } \\
\hline 3 & 122 & \multicolumn{2}{|c|}{$113^{\circ}$} & 2 & 1 & 2 & 4 \\
\hline 5 & 135 & \multicolumn{2}{|c|}{$101^{c}$} & 18 & 1 & 5 & 10 \\
\hline 7 & 66 & \multicolumn{2}{|c|}{$49^{\circ}$} & 4 & 8 & 1 & 4 \\
\hline 14 & 71 & \multicolumn{2}{|c|}{$26^{c}$} & 22 & 19 & 1 & 3 \\
\hline \multicolumn{8}{|l|}{ Weeks } \\
\hline 4 & 11 & 6 & 1 & 1 & 2 & 0 & 1 \\
\hline 5 & 35 & 24 & 4 & 3 & 2 & 2 & 0 \\
\hline 6 & 24 & 8 & 1 & 6 & 8 & 1 & 0 \\
\hline 8 & 18 & 12 & 3 & 1 & 1 & 1 & 0 \\
\hline \multicolumn{8}{|l|}{ Months } \\
\hline 3 & 18 & 12 & 4 & 2 & 0 & 0 & 0 \\
\hline 5 & 46 & 25 & 11 & 0 & 4 & 4 & 2 \\
\hline 6 & 8 & 4 & 0 & 0 & 1 & 1 & 2 \\
\hline 7 & 5 & 4 & 0 & 0 & 0 & 1 & 0 \\
\hline 12 & 8 & 3 & 0 & 0 & 0 & 3 & 2 \\
\hline 14 & 4 & 0 & 0 & 1 & 2 & 1 & 0 \\
\hline 30 & 5 & 3 & 0 & 0 & 0 & 1 & 1 \\
\hline 48 & 4 & 2 & 0 & 0 & 0 & 0 & 2 \\
\hline
\end{tabular}

B. Following Cutting of a Connective

$\begin{array}{crrrrrrr}\text { Weeks } & & & & & & \\ 4 & 4 & 4 & 0 & 0 & 0 & 0 & 0 \\ 6 & 17 & 16 & 0 & 0 & 1 & 0 & 0 \\ 8 & 9 & 7 & 0 & 2 & 0 & 0 & 0 \\ \text { Months } & & & & & & & \\ 3 & 11 & 10 & 0 & 0 & 1 & 0 & 0 \\ 6 & 5 & 4 & 0 & 1 & 0 & 0 & 0\end{array}$

a Time from making the lesion until the tissue was fixed.

${ }^{b}$ The level of regeneration assayed morphologically is encoded as follows: 0 , no sprouts crossed the lesion; $A$, sprouting across the lesion and up to halfway to the ganglion; $\mathrm{B}$, growth more than halfway to and/or barely into the target ganglion; $C$, regenerating axon has entered the target neuropil but shows few branches or varicosities; $D$, those cases where the regenerated axon shows many secondary branches and varicosities and goes out of at least one of the roots, but is clearly incomplete; $E$, those cases where the regenerate is indistinguishable from normal.

${ }^{c}$ In these cases categories 0 and $A$ were arbitrarily lumped together during the examination of the whole mounts.

processes were following a normal pathway, as labeled by the Lucifer Yellow-injected cells. The 15 branches, 85 varicosities, and 26 apparent contacts with the Lucifor Yellow-injected cell are fewer than normal.

Not all neurons that regenerated axons into the target ganglion and made apparent contacts there with normal types of targets were restricted to the normal pathway, however. Figure 5 shows a neuron with an axon that followed a clearly aberrant pathway to the next ganglion, yet many of the regenerated secondary branches and varicosities seem to have come into close apposition with a $T$ cell in that ganglion.

Although some neurons apparently never reconnected to targets, 5 of the 21 preparations examined a year or more after injury were indistinguishable from the normal preparations; another 7 had grown into the target ganglion and evidently formed synapses there. It is not clear how many of the normal-looking preparations were full regenerates and how many were fusions, but it seems likely that some of each were in the population. By mapping of sensory fields in the skin, where additional demands are placed on a cell as it attempts to regenerate fully, more light could be shed on the issue.

An important question is whether the injected cell within the target ganglion is a suitable marker for the normal pathway, since its axon is severed when the connective is crushed and also regenerates. We believe that it is suitable because we found no evidence that the target cell's secondary branches or apparent contacts in its own ganglion are significantly different from those of uninjured cells within the same animal. However, the numbers of branches and contacts were slightly higher for the target neurons and for uninjured neurons in the lesioned animal than those for the uninjured controls (Table I). A plausible explanation for these small differences is that the controls may have been younger than the regenerates, on the average, and that as the animal grows and the nervous system matures, the numbers of branches, varicosities, and contacts increase, which has aiready been shown for T cells (Musacchio and Macagno, 1982). Additionally, it is likely that the lesion induces limited changes throughout the nervous system (Jansen et al., 1974).

\section{Physiology of regenerated connections}

Recording the synaptic potentials evoked by $T$ cells. The $T$ cells make polysynaptic, excitatory chemical connections with $S$ cells and other T celis in adjacent ganglia in addition to electrical connections with these same cells (Baylor and Nicholls, 1969), and both types of connections can regenerate (Baylor and Nicholls, 1971). So that we could be certain that we were looking only at "direct" connections, we adopled the procedure of bathing the preparation in saline with $\left[\mathrm{Mg}^{2+}\right]$ elevated to block chemical synaptic transmission, as used by Baylor and Nicholls (1971). Of course, the electrical connection with the $S$ cell is indirect, as it is mediated by the $C$ cells, but in solutions with elevated $\left[\mathrm{Mg}^{2+}\right]$, the $\mathrm{C}$ cells act as an electrical extension of the $S$ cell.

The normal electrical connection that is measured between two $T$ cells or between $T$ and $S$ cells in separate ganglia is usually about $1 \mathrm{mV}$, but can be as large as $2 \mathrm{mV}$ (Figs. $3 \mathrm{c}$ and $4 \mathrm{c}$ ). The variation seems to be due only partly to the quality of the electrode impalements and, over a wide range, has little dependence on cell input resistance. Although the synaptic noise is reduced in elevated $\left[\mathrm{Mg}^{2+}\right]$, it is difficult to measure reliably synaptic potentials smaller than about a third of a millivolt without signal averaging, a procedure that was used on all of the more than $75 \mathrm{~T}$ cell pairs examined physiologically in regenerating preparations.

Regenerated synaptic connections. Most recordings of synaptic potentials were made in regenerated preparations at 6 weeks or later (Table III). The sizes of the synaptic potentials recorded in the T cells varied widely, the smallest being about $10 \mu \mathrm{V}$. A comparison of the amplitudes, normalized to the number of contacts between

Figure 2. Micrographs of the connectives between ganglia in three lesioned animals. Anterior is to the right in all panels. The bar in a represents $100 \mu \mathrm{m}$ in $a$ and $20 \mu \mathrm{m}$ in $b$ and $c$. a. The location of the lesion is indicated by the region between the open arrows. The many fine, beaded branches of both HRPand Lucifer Yellow-filled T cells are indicated by the arrowheads on the right (anterior) side of the lesion. This animal had been lesioned 14 months prior to the analysis. It is evident that both the HRP-and Lucifer Yellow-filled cells have regenerated across the region of the lesion, but the sprouts of the HRP-filled cell did not reach the ganglion (out of the picture at right). In the contralateral connective and out of focus in this micrograph, the HRP-filled T cell axon regenerated well into the ganglion and made many contacts with the local T cell. $b$, Detail of the tip of an HRP-filled T cell axon which apparently grew along or in contact with branches of the Lucifer Yellow-filled T cell. This right connective was crushed to the left of this region 6 moths prior to the analysis, but this axon grew only about halfway $(1.5 \mathrm{~mm})$ toward the next anterior ganglion. $c$, Two sprouts of an HRP-filled axon in the right connective lesioned 4 weeks prior to the analysis. The lower sprout grew along the Lucifer Yellow-filled axon and entered the ganglion on the right, in which many Lucifer Yellow-filled branches appear out of focus. The upper sprout grew along an abnormally medial tract and failed to enter the ganglion. 

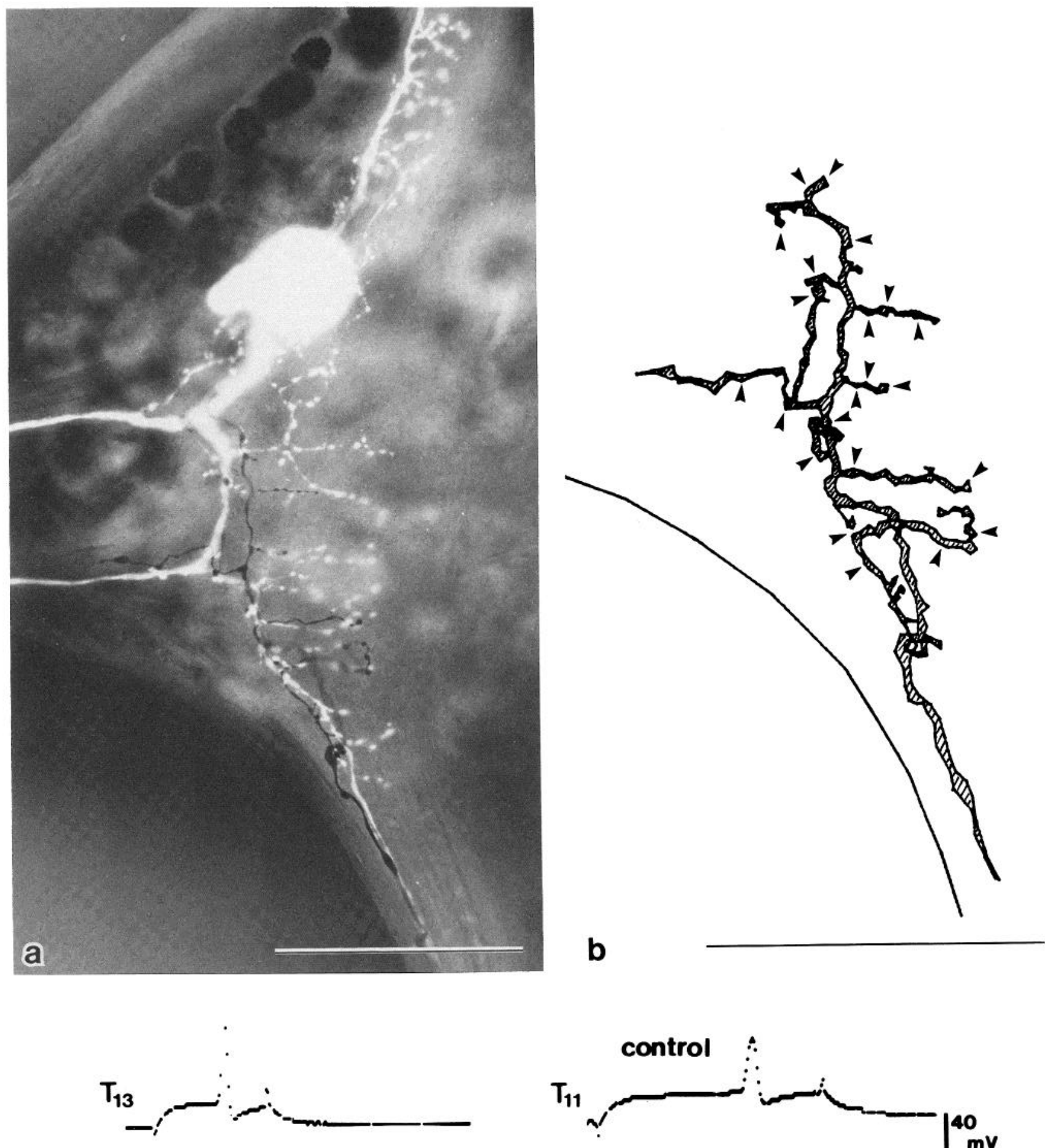

$\mathrm{S}_{12}$
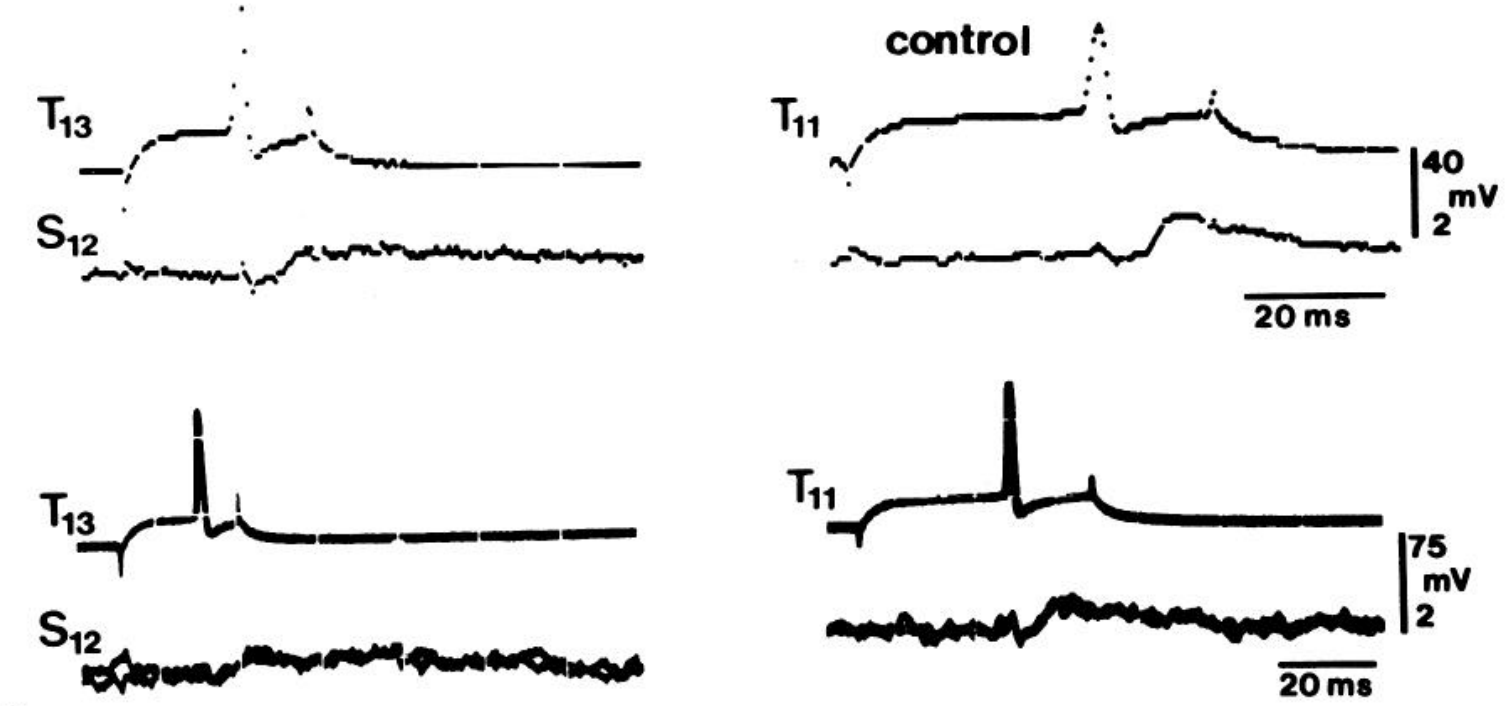

C

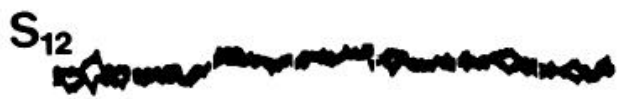


the cells and expressed as microvolts per contact, revealed a clear pattern. For the approximately $1-\mathrm{mV}$ synaptic potential that was recorded in normal preparations there were about 50 apparent contacts, thus a signal of $20 \mu \mathrm{V} /$ contact was recorded. Half that value or less was typically recorded for the regenerated synaptic potentials (Fig. $4 \mathrm{c}$ ), the value tending to increase for larger synaptic potentials and at later regeneration times, whereas apparent contacts upon the target cell from cells within its own ganglion remained in the normal range. Although the relationship was only correlative, if each possible contact contributed to the total synaptic potential that was measured, then in the earlier stages of regeneration the transmission at individual contacts was evidently reduced.

One explanation for the smaller number of microvolts per contact for the regenerates, suggested by the morphology of the postsynaptic cells and the distribution of contacts upon them, is that the nascent synapses occur at physically and, presumably, electrically more distant points from the cell body within which the recording microelectrode is placed. Although no systematic measurements of rise times have been made, casual observation of physiology and morphology support this interpretation. Two other explanations remain plausible, that the new or growing contacts simply do not deliver the current that the mature contacts do, or that some of the apparent contacts, such as those not at varicosities, are not synapses.

To measure the success of regeneration of synapses with higher order neurons, we also recorded from $S$ interneurons within the target ganglia. $\mathrm{As}$ shown in Figure $3 c$, the physiological results were similar to those obtained with $T$ cells as targets. When both types of cells, $T$ and $S$, were tested as postsynaptic, the sizes of the synaptic potentials were in most cases similar (Table Iil). Just as the apparent contacts between $T$ cells are normally distributed along the length of the neuropil within the ganglion, so too are the lines of communication with the $S$ cells through the $C$ cells (Fig. 1C). Thus, we might expect explanations for the reduced normalized potentials at nascent contacts to be similar for $T$ cells and for $S$ cells.

To test whether the regeneration of each axon was independent of others, we looked for clustering of regenerates in a sample of 43 $T_{V}$ and $T_{L}$ cells that were examined with signal averaging techniques for functional reconnection. Eighteen cells had reconnected with some normal targets; in six connectives only one axon had reconnected and in six others both $T_{V}$ and $T_{L}$ had reconnected, indicating that there was no strong clustering

Another index of independence was whether regeneration by axons in one connective was accompanied by successful regeneration in the other. A comparison of regeneration in 29 pairs of connectives showed that there was no regeneration in 8 of the pairs, axons had regenerated in both connectives in 7 of the pairs, and of the remaining 14 there was regeneration in the left or the right, but not both. Given a probability of 0.48 for regeneration in a single comective, and if growth in the two connectives were independent, we would have predicted an incidence for neither:both:left or right combined, in the ratio 0.27:0.23:0.50. In fact, the measured incidence was $0.27: 0.24: 0.49$, suggesting that successful regeneration occurred independently in the two connectives and that there was no clustering. These results would not be expected if regeneration were, for whatever reason, favored in some animals and discouraged in others.

Functional connections were not detected before axons had grown in the neuropil and varicosities were elaborated. But once synaptic potentials could be recorded, there were invariably several varicosities on the regenerated axon and several points of apparent contact with the target. That we did not measure synaptic potentials for preparations with only one or two apparent contacts in the target ganglion was not surprising since we did not reliably detect synaptic potentials smaller than about $20 \mu \mathrm{V}$, which would be the transmission expected at several newly regenerated contacts functioning in unison.

\section{Discussion}

Limits to full regeneration. Touch sensory neurons in many cases became reconnected to each other (in confirmation of earlier findings; e.g., Baylor and Nicholls, 1971) and to S neurons after their axons were interrupted. However, sensitive physiological recording techniques showed that regeneration rarely restored full electrical communication between cells. By morphological criteria, about $18 \%$ of the $626 \mathrm{~T}$ cells examined showed at least some regeneration of branches and varicosities into their normal region of the ganglion. The relatively low rate of successful repair contrasts with the regeneration of the electrical synapses in the medial connective between $S$ cells, in which the connections were restored to nearly normal efficacy between at least $80 \%$ of cell pairs after lesions like those that were used to sever the axons of $T$ cells (Muller and Carbonetto, 1979). Part of the explanation for the difference may be that as axonal and synaptic complexity increased, the probability of full restoration diminished, but there may also simply be differences in the ability of various types of modalities of cells to grow, as has already becn noted for axons growing in chains of ganglia main tained in tissue culture medium (Wallace et al., 1977).

The first barrier to $T$ cell growth was, of course, the lesion itself In most cases of failure to regenerate, the severed axon had not crossed the lesion, a result that was particularly frequent with cuts (Table II). In some cases the axon had reversed direction and grown toward its own ganglion, at times entering it and branching there. According to Muller and Carbonetto (1979), the S cell axons rarely failed to cross a similar crush. Since $S$ cell axons travel in a separate small connective with only a $1 / 30$ the number of axons (100 versus 3000; Wilkinson and Coggeshall, 1975), the difference between S cell and $T$ cell axons could have been related to the complexity of the connectives at the site of the lesion and the inability of the regeneratıng axons to find a suitable pathway, although basic cellular differences or some other factors could be significant. Ramón y Cajal (1928) already pointed out that lack of growth beyond the lesion can be the principal impediment to successful regeneration. But even the presence of a pathway capable of promoting growth has been inadequate to ensure functional reconnection in mammals (Aguayo et al., 1982).

Pathways and their role. Regeneration along the normal route to the ganglion was generally associated with accurate reconnection and was apparently a prelude to it. Most axonal branches that crossed the lesion did not immediately find the normal pathway, as marked by the axon of the $T$ cell in the adjacent ganglion; but typically, if synaptic transmission was restored, regenerating branches appeared to have found their usual pathway in the connective: they often seemed to have followed the axon of the homologue into the target ganglion. As in the unoperated preparation, however, the two axons were not often in apparent contact with one another. There are normally six $T$ cell axons in a connective and, since distal stumps do not rapidly disappear, there are more in the regenerated preparations. Thus, we cannot be certain whether a stained $T$ cell axon is accompanied by an unstained $T$ cell axon in the connective or not. We aiso observed that the regenerated $T$

Figure 3. Partial regeneration into the adjacent anterior ganglion by a T cell axon severed ? months previously. a, The regenerated axon, filled with HRP

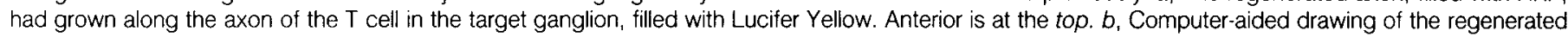

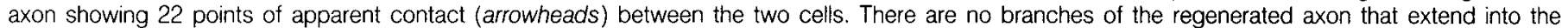

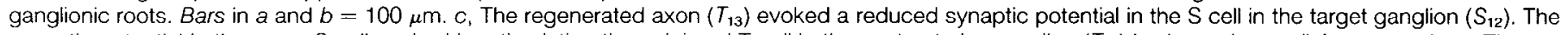

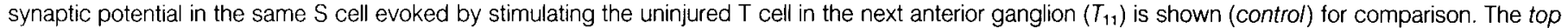
pairs of traces represent averages of 32 sweeps, two of which are shown superimposed in the bottom pairs. 

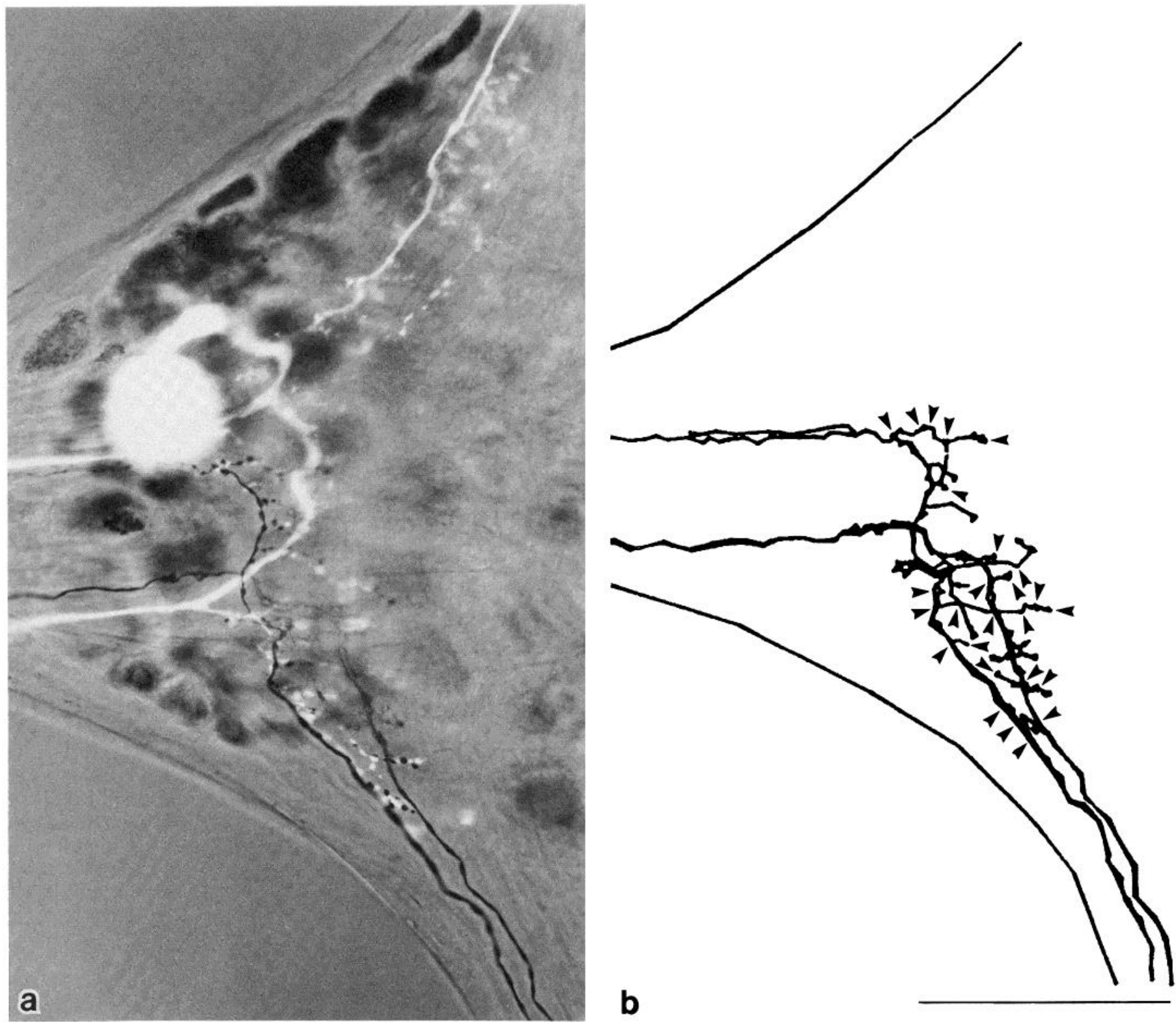

Figure 4. Partial regeneration into the adjacent anterior ganglion by a T cell axon lesioned 1 year before analysis. This is an exceptional case in that two collaterals have grown into the ganglion, each of which gives rise to numerous branches and continues out of one of the two roots. The degree of regeneration attained by this axon is considerably greater than that of the axon shown in Figure 3, but it is still incomplete. a, Micrograph of the left side of the ganglion: the axonal collateral on the left grew along the axon of the target T cell (filled with Lucifer Yellow) and sends a branch out of the anterior root; the other one grew along a somewhat more medial pathway and sends a branch out of the posterior root. Anterior is at the top. Bars in $a$ and $b=100 \mu \mathrm{m}$. $b$, Computer-aided drawing of the regenerated axon showing 26 points of apparent contact (arrowheads) between the two cells. $c$, The regenerated axon $\left(T_{12}\right)$ evoked a reduced synaptic potential in its target $T$ cell $\left(T_{11}\right)$. The synaptic potential in the same target cell evoked by stimulating an uninjured T cell in the next anterior ganglion $\left(T_{10}\right)$ is shown here (control) for comparison. The top pairs of traces represent averages of 32 sweeps, two of which are shown superimposed in the bottom pairs.

cell axons followed the local $\mathrm{T}$ cell closely within the ganglionic neuropil and out of the lateral roots toward the periphery. This was particularly notable in some cases, such as the one shown in Figure 5 , where pathways to the ganglion were aberrant, but those within the ganglion were normal.

It is significant in considering the importance of the pathway that recovery from lesions of mammalian nerve occurs best after crushes rather than cuts, and that regeneration of sensory fibers along the normal pathway can produce normal patterns of innervation of target structures in the skin (Horch, 1979; Dykes and Terzis, 1979). However, in these cases it is not known whether reinnervation is by the original neurons, or whether cells within the population are interchangeable. An intact normal pathway may not always be required for accurate regeneration, however, and indeed in mammalian neonates, neurons of the pyramidal tract can regenerate to normal targets along aberrant (but consistent) pathways (Kahlil and Reh, 1979). Regenerating retinal axons in amphibians can reach tectal targets by circuitous routes (Fujizawa, 1981).

Alternative mechanisms for reconnection. A small fraction of cells reconnected by rejoining the severed $T$ cell stump, although as reported previously (DeRiemer et al., 1983), no recovery occurred in less than 2 days. Because axons grow into the ganglion and 


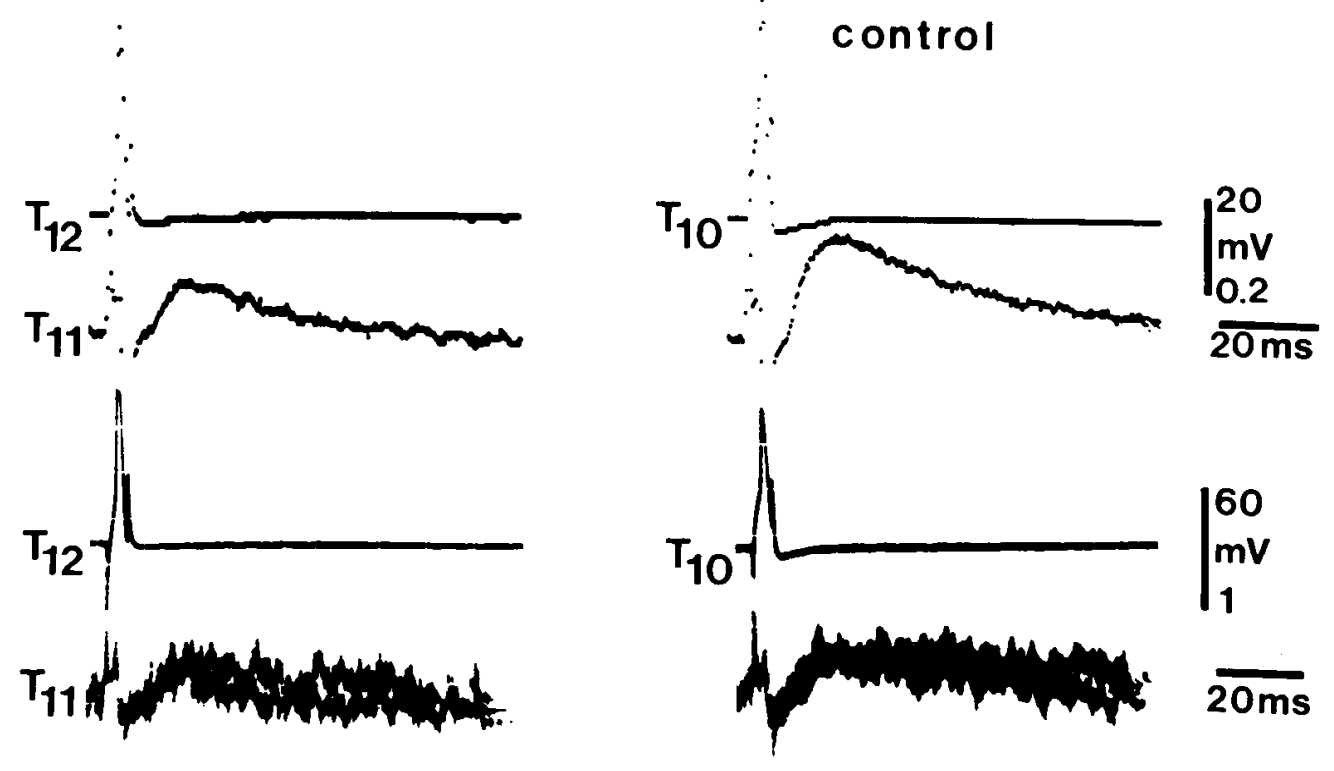

C

Figure $4 c$

TABLE III

Analyses of regenerated anterior arbors of $T$ cells

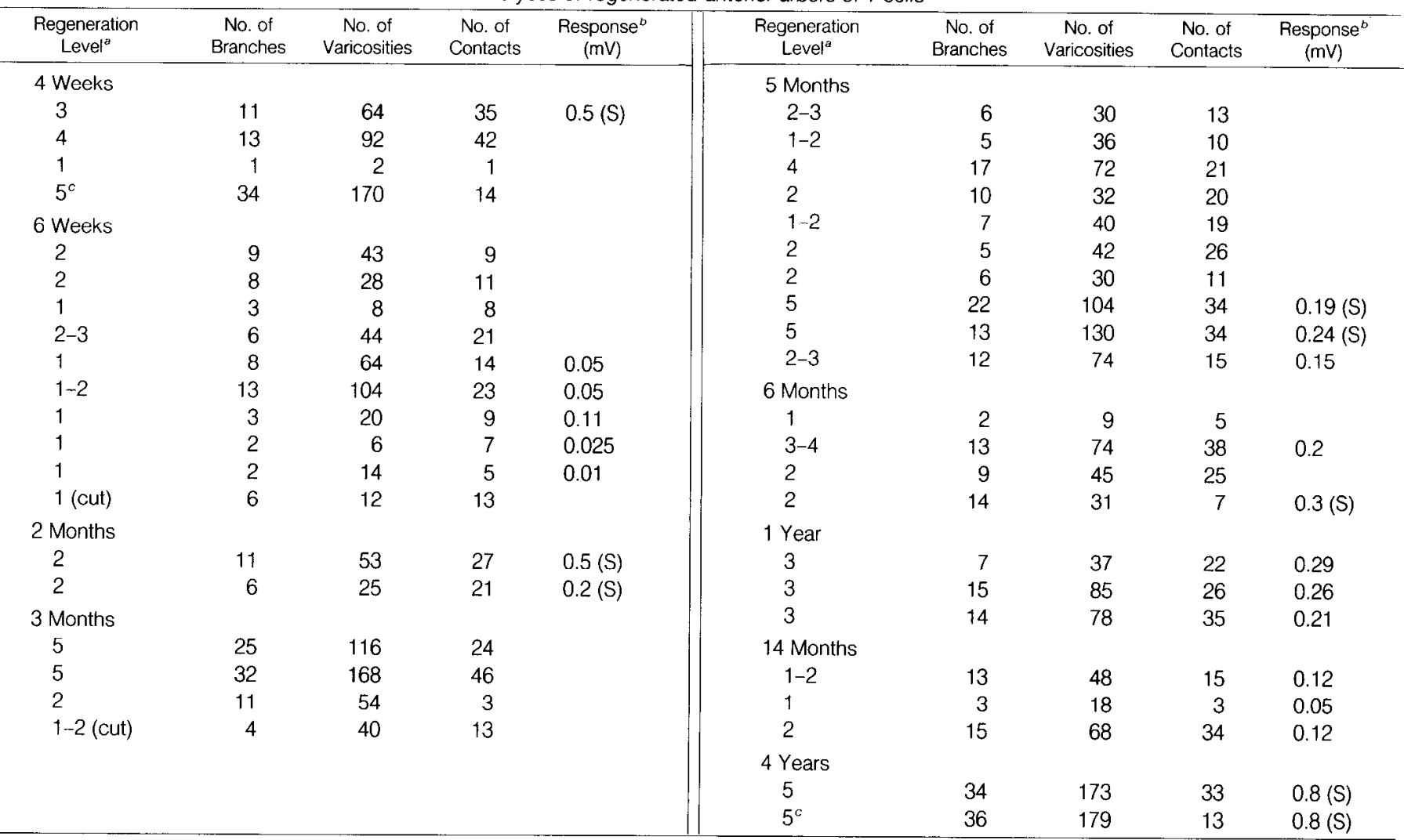

a The level of regeneration, assayed morphologically, is encoded as follows: 1, regenerated processes just entering the target ganglion, with a few branches and varicosities; 2 , growth of a process out of only one root; 3 , growth of processes out of both roots, but relatively few branches and varicosities; 4, an essentially normal but somewhat smaller arbor than one finds in a normal cell; 5 , a regenerated arbor indistinguishable from a normal one.

${ }^{b}$ The synaptic response in the target $T$ cell or, where noted by (S), in the target $S$ cell. These values should be compared with the normal responses in a $\mathrm{T}$ cell or an S cell when stimulating a T cell in the next posterior ganglion, which fall in the range of 0.8 to $1.2 \mathrm{mV}$. Ordinarily, somewhat smaller responses are obtained by stimulating a $T$ cell in the next anterior ganglion $(0.6$ to $1.0 \mathrm{mV})$, which were used as controls in these experiments. No physiological measurements were attempted in the cases for which values are not reported

${ }^{c}$ The number of apparent contacts in these cases is low because the target $T$ cell is of the dorsal type ( $\left.T_{0}\right)$. 


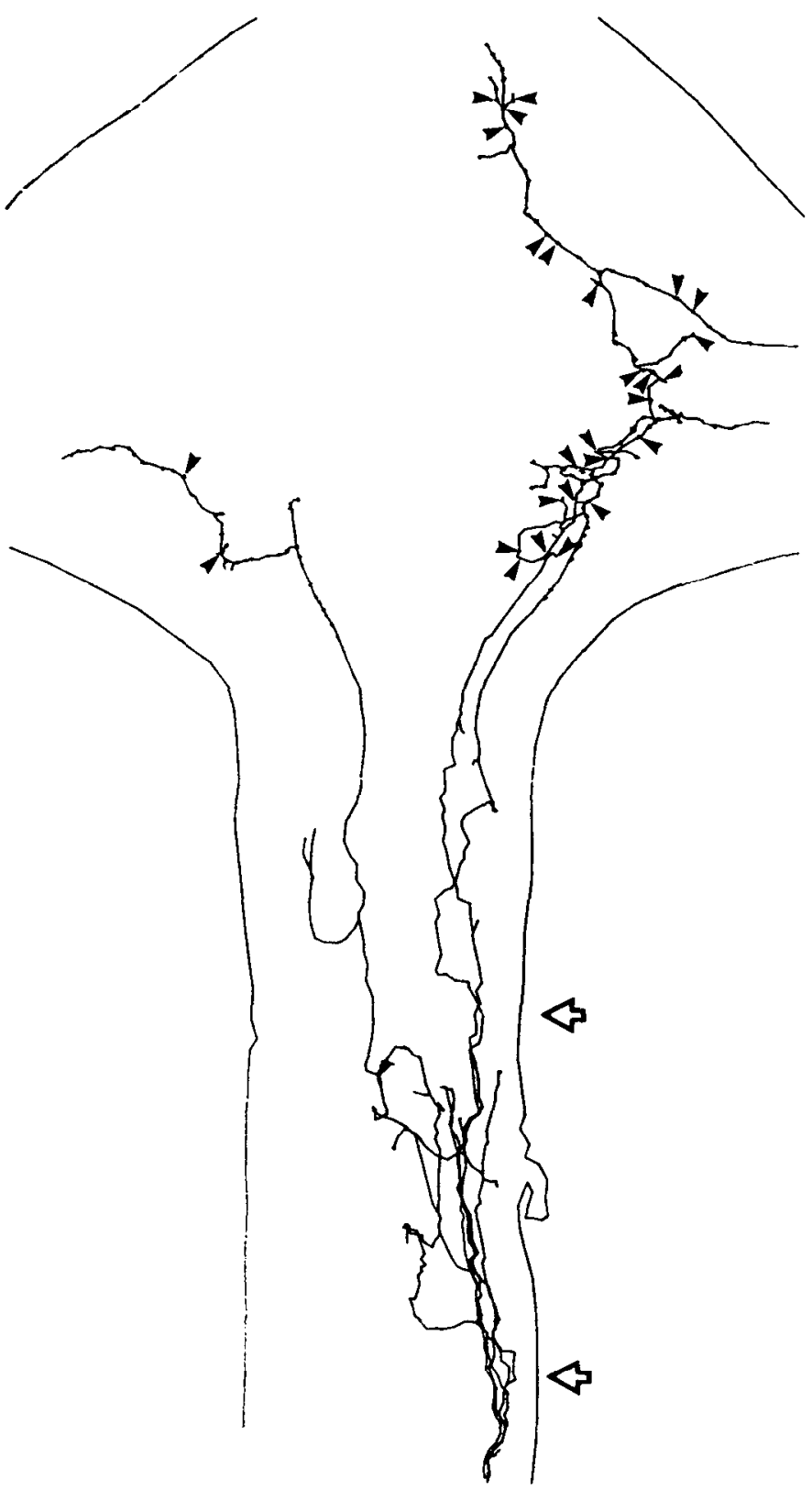

Figure 5. Drawing of an abnormal 5-month regenerate. There is extensive branching of the axon at the site of the crush, some branches heading anteriorly (top) and others posteriorly back to the cell's own ganglion. Three branches that cross the lesion grew into the target ganglion: two along the ipsilateral and one along the contralateral connective. This last one took an unusual route into the target ganglion, one which is significantly more medial than the normal one. All three also made apparent contacts with local T cells, 24 ipsilaterally and 2 contralaterally, at the sites indicated by the arrowheads. A synaptic potential of $0.24 \mathrm{mV}$ was measured in the ipsilateral target $T$ cell when the regenerated axon was stimulated.

arborize within a fortnight, the mechanism for regencration of com plete arbors at later times, whether by fusion or by progressive growth, was unclear. However, even after 2 years, when growth might have been expected to have stopped, regenerated arbors were in several cases incomplete.

During regeneration of $S$ cell axons (Carbonetto and Muller, 1977) and perhaps also of pressure mechanosensory cells (Elliott and Muller, 1983) in the leech, the growing axon forms an electrical synapse on its distal stump rather than rejoining with it and thereby rapidly restores transmission. Because restoration of transmission (examined in solutions expected to block polysynaptic, chemical excitation) was always accompanied by growth into the target ganglion, there was no evidence for functional repair of $T$ cells by an electrical synapse with the severed distal stump.

Functioning of new connections. Not only did the axons that grew to the target ganglion almost invariably reconnect with appropriate cells there, but there was a correlation between the number of apparent contacts with the target $T$ cells and the strength of the new synaptic connections. Regenerated contacts, however, were weaker than controls, showing a strength of 5 to $10 \mu \mathrm{V} /$ contact, on average, in contrast with a normal average size of $20 \mu \mathrm{V} /$ contact. It would, of course, be useful to examine each of the presumed contacts observed under the light microscope with electron microscopy to prove that they are the sites of electrical synapses between the cells and to determine whether the extent of synaptic contact is reduced in the regenerates. Unfortunately, such an analysis is difficult with the presently available techniques.

Since functional recovery was examined principally in solutions that were expected to block chemical synaptic transmission, it is possible that enhanced chemical synaptic transmission compensated for whal might be viewed as a deficit in electrical transmission. Although a careful test of this hypothesis has not been performed, a few experiments that were performed in saline lacking $\mathrm{Mg}^{2+}$ and those reported by Baylor and Nicholls (1971) do not support it.

The recent demonstration of synapse regeneration by defined populations of sensory neurons in bullfrog spinal cord (Sah and Frank, 1984) provides several parallels to our findings with single, identified neurons. Sensory axons grew to normal locations within the dorsal horn and made physiologically measurable synapses with their normal complement of targets. The strength of the synaptic connections was lower than normal, however, presumably because some of the axons had not regenerated to their targets, but also perhaps because synaptic input from individual fibers was reduced, as in the leech.

In conclusion, $T$ cells regenerated functional connections with their normal targets in adjacent ganglia despite morphologically abnormal regeneration, but successful reconnection was most likely to occur when the axon followed its normal pathway and branched in its usual region of the ganglion. Evidently those neurites that were unsuccessful in finding the target retracted, since fewer sprouts were seen at later times of regeneration, whereas those that reached the neuropil elaborated varicosities and formed synapses. Transmission between regenerates was usually weaker than normal, partly because there were fewer contacts, but also perhaps because the contacts that were made were immature and more distant from the recording cell in the target cell body. Among the important questions that remain are: how does the regenerating neuron recognize its pathway in the connective, what conditions promote fusion with the distal stump, thereby restoring full function, and how selective is regeneration, i.e., are mistakes made and why are "wrong" paths taken? By obtaining the answers to these questions in the leech, where individual cells can be identified, their growth traced, and synapse formation monitored, we can more easily gain insights into nerve repair in more complex organisms.

\section{References}

Aguayo, A. J., S. David, P. Richardson, and G. Bray (1982) Axonal elongation in peripheral and central nervous system transplants. Adv. Cell. Neurobiol. 3: $215-234$.

Baylor, D. A., and J. G. Nicholls (1969) Chemical and electrical synaptic connections between cutaneous mechanoreceptor neurons in the central nervous system of the leech. J. Physiol (Lond.) 203: 591-609.

Baylor, D. A., and J. G. Nicholls (1971) Patterns of regeneration between individual nerve cells in the central nervous system of the leech. Nature 232: $268-270$.

Carbonetto, S., and K. J. Muller (1977) A regenerating neuron in the leech can form an electrical synapse on its severed axon segment. Nature 267 : $450-452$. 
DeRiemer, S. A., and E. R. Macagno (1981) Light microscopic analysis of contacts between pairs of identified leech neurons with combined use of horseradish peroxidase and Lucifer Yellow. J. Neurosci. 1: 650-657.

DeRiemer, S. A., E. R. Macagno, and K. J. Muller (1981) Overlap of interganglionic dendritic fields of mechanosensory cells in leech segmental ganglia. Biol. Bull. 161: 341-342.

DeRiemer, S. A., E. J. Elliott, E. R. Macagno, and K. J. Muller (1983) Morphological evidence that regenerating axons can fuse with severed axon segments. Brain Res. 272: 157-161.

Dykes, R. W., and J. K. Terzis (1979) Reinnervation of glabrous skin in baboons: Properties of cutaneous mechanoreceptors subsequent to nerve crush. J. Neurophysiol. 42: 1461-1478.

Elliott, E. J., and K. J. Muller (1983) Sprouting and regeneralion ol serısory axons after destruction of ensheathing glial cells in the leech central nervous system. J. Neurosci. 3: 1994-2006.

Fernandez, J. H., and M. S. G. rernandez (1974) Morphological evidence for an experimentally induced synaptic field. Nature 251: 428-430.

Fujizawa, H. (1981) Persistence of disorganized pathways and tortuous trajectories of the regenerating retinal fibers in the adult newt $C y n o p s$ pyrroghaster. Dev. Growth Differentiation 23: 215-219.

Horch, K. W. (1979) Guidance of regrowing sensory axons after cutaneous neve lesions in the cat. J. Neurophysiol. 42: 1437-1449

Jansen, J. K. S., K. J. Muller, and J. G. Nicholls (1974) Persistent modification of synaptic interactions between sensory and motor nerve colls following discrete lesions in the central nervous system of the leech. J. Physiol (Lond.) 242: 289-305

Kahlil, K., and T. Reh (1979) Regrowth of severed axons in the neonatal central nervous system: Establishment of normal connections. Science 205: $1158-1161$.

Macagno, E. R., K. J. Muller, W. B. Kristan, S. A. DeRiemer, R. R. Stewart, and B. Granzow (1981) Mapping of neuronal contacts with intracellular injection of horseradish peroxidase and lucifer yellow in combination. Brain Res. 217: 143-149.

Macagno, E. R., S. A. DeRiemer, and K. J. Muller (1982) Regeneration of effective but aberrantly distributed synapses by sensory neurons in the leech CNS. Soc. Neurosci. Abstr. 8: 868.

Mason, A., and K. J. Muller (1982) Axon segments sprout at both ends: Tracking growth with fluorescent D-peptides. Nature 296: 655-657.

Muller, K. J. (1979) Synapses between neurons in the central nervous system of the leech. Biol. Rev. 54: 99-134.

Muller, K. J. (1982) Cell recognition and specific synapse formation. In Repair and Regeneration of the Nervous System, J. G. Nicholls, ed., pp. 155-
171, Springer-Verlag, Berlin

Muller, K. J., and S. Carbonetto (1979) The morphological and physiological properties of a regenerating synapse in the CNS of the leech. J. Comp. Neurol. 185: 485-516.

Muller, K. J., and U. J. McMahan (1976) The shapes of sensory and moter neurones and the distribution of their synapses in ganglia of the leech: A study using intracellular injection of horseradish peroxidase. Proc. R. Soc. Lond. (Biol.) 194: 481-491

Muller, K. J., and J. G. Nicholls (1981) Regeneration and plasticity. In Neurobiology of the Leech, K. Muller, J. Nicholls, and G. Stent, sts. pp. 197-226, Cold Spring Harbor Laboratory, Cold Spring Harbor, NY.

Muller, K. J., and S. A. Scott (1979) Correct axonal regeneration after target cell removal in the central nervous system of the leech. Science 206: $87-$ 89

Muller, K. J., and S. A. Scott (1981) Transmission at a "direct" electrical connexion mediated by an interneurone in the leech. J. Physiol. (Lond.) 311: 565-584

Muller, K. J., J. G. Nicholls, and G. S. Stent (1981) Neurobiology of the Leech, Cold Spring Harbor Laboratory, Cold Spring Harbor, NY.

Musacchio, M., and E. R. Macagno (1982) Quantitative aspects of growth of an identified neuron in the leech Hirudo medicinalis. Biol. Bull. 163: 388.

Nicholls, J. G., and D. A. Baylor (1968) Specific modalities and receptive fields of sensory neurons in the CNS of the leech. J. Neurophysiol. 31: $740 \cdots 756$

Nicholls, J. G., and D. Purves (1970) Monosynaptic chemical and electrical connexions between sensory and motor cells in the central nervous system of llie leech. J. Physiol. (Lond.) 209: 647-667.

Ramón y Cajal, S. (1928) Degeneration and Regeneration of the Nervous System, R. M. May, ed. and transl., Hafner Press, New York.

Ready, D., and J. G. Nicholls (1979) Identified neurones isolated from leech CNS make selective connections in culture. Nature 281: 67-69.

Sah, D. W. Y., and E. Frank (1984) Regeneration of sensory-motor synapses in the spinal cord of the bullfrog. J. Neurosci. 4: 2784-2791.

Wallace, B. G., M. Adal, and J. G. Nicholls (1977) Regeneration of synaptic connexions of sensory neurones in leech ganglia in culture. Proc. R. Soc Lond. (Biol.) 199: 567-585.

Wilkinson, J. M., and R. E. Coggeshall (1975) Axonal numbers and sizes in the connectives and periphcral nerves of the leech. J. Comp. Neurol. 162: 387-396

Yau, K. -W. (1976) Receptive fields, geometry and conduction block of sensory neururies in the CNS of the leech. J. Physiol. (Lond.) 263: 513538. 